\title{
Influência do manejo agrícola na suscetibilidade dos solos à erosão na sub-bacia hidrográfica do rio São Romão, Nova Friburgo/RJ.
}

\author{
Raphael Rodrigues Brizzi ${ }^{1}$ \\ Andréa Paula de Souza ${ }^{2}$ \\ Alexander Josef Sá Tobias da Costa ${ }^{3}$
}

Resumo: O avanço da pastagem e agricultura sobre a Mata Atlântica, turismo, loteamentos, e o manejo inadequado colaboram, cada vez mais, para a degradação dos solos na APA de Macaé de Cima, em Nova Friburgo, RJ. O estudo visa à compreensão de parâmetros erosivos em diferentes usos do solo, tais como florestapastagem-cultivo, nas profundidades de 0-10 e 10-20 cm, sendo avaliados a distribuição granulométrica, densidade aparente, densidade das partículas, microporosidade, macroporosidade e porosidade total, carbono orgânico e $\mathrm{pH}$. Os resultados ratificam diversas pesquisas desenvolvidas na relação do uso do solo com a erosão e demostram ser as áreas de pastagem e cultivo as mais degradadas, sendo necessário o fortalecimento do plano de manejo da APA. Assim, destaca-se a importância da floresta na estruturação dos solos frente ao desenvolvimento de processos erosivos, em que as atividades antrópicas na região potencializam a fragilidade inerente ao sistema avaliado, ocasionando a mudança da paisagem.

Palavras-chave: Uso do solo; Propriedades físico-químicas; Erodibilidade.

\section{INFLUENCE OF AGRICULTURAL MANAGEMENT ON SOIL SUSCETIBILITY TO EROSION HYDROGRAPHIC SUB-BASIN OF SÃO ROMÃO RIVER, NOVA FRIBURGO/RJ}

\begin{abstract}
Pasture and agriculture expansion in the Atlantic forest (Mata Atlântica), tourism, property development, and inadequate management increasingly collaborate to soil degradation in the Environmental Protection Area (EPA) of Macaé de Cima, in Nova Friburgo - RJ. This study aims to understand erosion parameters in types of different soil uses such as forest-pasture-cultivation in 0-10 and 10-20 cm depths, and analyses of particle size distribution, apparent density, particle density, microporosity, macroporosity and total porosity, organic carbon and $\mathrm{pH}$ were conducted. Results confirm several researches on the relationship between soil use and erosion and demonstrate that pasture and cultivation areas are the most degraded ones, which becomes necessary the strengthen of the EPA management plan. Therefore, we highlight the importance of the forest on soil structure in view of the development of erosive processes in an area where human activities intensify the inherent fragility of the evaluated system, resulting in landscape change.
\end{abstract}

\footnotetext{
${ }^{1}$ Instituto Federal de Educação, Ciência e Tecnologia do Rio de Janeiro - IFRJ, E-mail: raphael.brizzi@ifrj.edu.br

${ }^{2}$ Faculdade de Educação da Baixada Fluminense - FEBF/UERJ, E-mail: andreaps.uerj@gmail.com

${ }^{3}$ Universidade do Estado do Rio de Janeiro - UERJ, E-mail: ajocostageo@gmail.com

Estudos Geográficos, Rio Claro, 15(2): p-p, jul./dez. 2017 (ISSN 1678-698X)

http://www.periodicos.rc.biblioteca.unesp.br/index.php/estgeo
} 
Keywords: Soil use; physical and chemical properties; erodibility.

\section{INTRODUÇÃO}

O avanço das áreas de pastagem e da agricultura sobre a Mata Atlântica, turismo, loteamentos, cortes de estradas e os manejos inadequados cada vez mais colaboram para a erosão dos solos e as mudanças na paisagem. Além disso, tem-se a ação antrópica como um agente intensificador de degradação, o que se torna relevante na modelagem do relevo (AB'SABER, 2003).

De acordo com Brady (1989), a erosão é o fator mais importante na destruição dos solos no mundo. Cerca de $15 \%$ das terras mundiais sofrem desse processo, sendo que, $56 \%$ desse total, sofrem de erosão acelerada (BOARDMAN, 2009), o que acarreta na mudança da paisagem e de seu valor em áreas com forte potencial turístico.

Silva et al. (2011) destacam que os fatores que mais afetam os indicadores de qualidade dos solos (porosidade, estrutura, $\mathrm{pH}$, saturação de bases, matéria orgânica e etc.) são determinados pela pressão demográfica, a disputa de terras, e pela necessidade de cada cultura, ocasionando a alteração dos solos e do meio ambiente. Esses têm como resultado o desmatamento, o uso intensivo das áreas de plantio sob monocultura e, até mesmo, o abandono das terras (LARSON e PIERCE, 1994, LAL, 1999).

Em relação à conservação do solo e ao seu uso mais eficaz, Bigarella, Becker e Santos (2007) afirmam que o desenvolvimento de um perfil de solo em regiões de clima úmido necessita, aproximadamente, de 100 a 200 anos para se formar. Isso se o solo estiver sob intensa cobertura vegetal (florestas), que irá contribuir e/ou acelerar os processos intempéricos, estando esse fenômeno atrelado, principalmente, à temperatura e à quantidade de água disponível no seu processo de formação.

Para que haja compreensão dessa dinâmica é necessário que se entenda que estas interações estão associadas a fatores geológico-geomorfológicos, climáticos, biológicos e de como o Homem se organiza no espaço geográfico, sendo importante dialogar com as escalas de ocorrência dos processos, pois, do contrário, o manejo e as perdas de solo no Brasil e no mundo tornar-se-ão insustentáveis e/ou irreversíveis visto que o solo não é um recurso renovável, a curto prazo.

A falta de planejamento do uso da terra em bacias hidrográficas torna mais complexa a relação Homem-Natureza, tendo em vista o desconhecimento da estrutura natural frente à inserção de novas variáveis pela ação antrópica. Além disso, o desconhecimento ou o surgimento/utilização indiscriminados dos usos (pastagens, cultivo e impermeabilização do uso do solo para atender a ocupação urbana), sem um estudo prévio de potencialidade das terras, afeta o gerenciamento dos recursos hídricos e dos ecossistemas.

Nesse contexto, a bacia hidrográfica do rio Macaé, no norte do Estado do Rio de Janeiro, apresenta cada vez mais significativas feições erosivas e de movimentos coletivos de massa, cuja causa principal é o mosaico indiscriminado de usos do solo em diferentes paisagens, além do manejo inadequado praticado em cada um deles associado às altas declividades existentes nessa região. 
Trabalhos como os de Lima et al. (2008), Mendes (2010), Loureiro et al. (2011) e Loureiro (2013) justificam a ocorrência desses fenômenos nos municípios que contemplam a bacia hidrográfica do Rio Macaé e acrescentam a importância de novos estudos que possibilitem subsidiar a compreensão da dinâmica entre sociedade-natureza e seus impactos diretos.

Nessa perspectiva, o trabalho tem como objetivo avaliar a suscetibilidade dos solos à erosão em uma sub-bacia hidrográfica do rio Macaé a partir de propriedades físicas e químicas em três tipos de uso do solo, de modo que os resultados obtidos venham subsidiar projetos voltados para o manejo realizado dentro da Área de Proteção Ambiental Estadual de Macaé de Cima, haja vista a sua importância na conservação de mananciais, no controle do fluxo de água e na redução do aporte de sedimentos no canal principal dos terços médio e inferior de toda bacia hidrográfica do rio Macaé.

\section{1 ÁREA DE ESTUDO}

A sub-bacia hidrográfica do rio São Romão (figura 1), com área de 21,20 km², está localizada no alto curso do rio Macaé na divisa do município de Nova Friburgo com o município de Macaé, limitada pelas coordenadas 22 $19^{\prime} 17^{\prime \prime}, 2^{\circ} 21^{\prime} 33^{\prime \prime} \mathrm{S}$ e $42^{\circ} 16^{\prime} 34^{\prime \prime}, 42^{\circ} 54^{\prime} 11^{\prime \prime} \mathrm{W}$.

Figura 1: Mapa da sub-bacia hidrográfica do rio São Romão, Nova Friburgo /

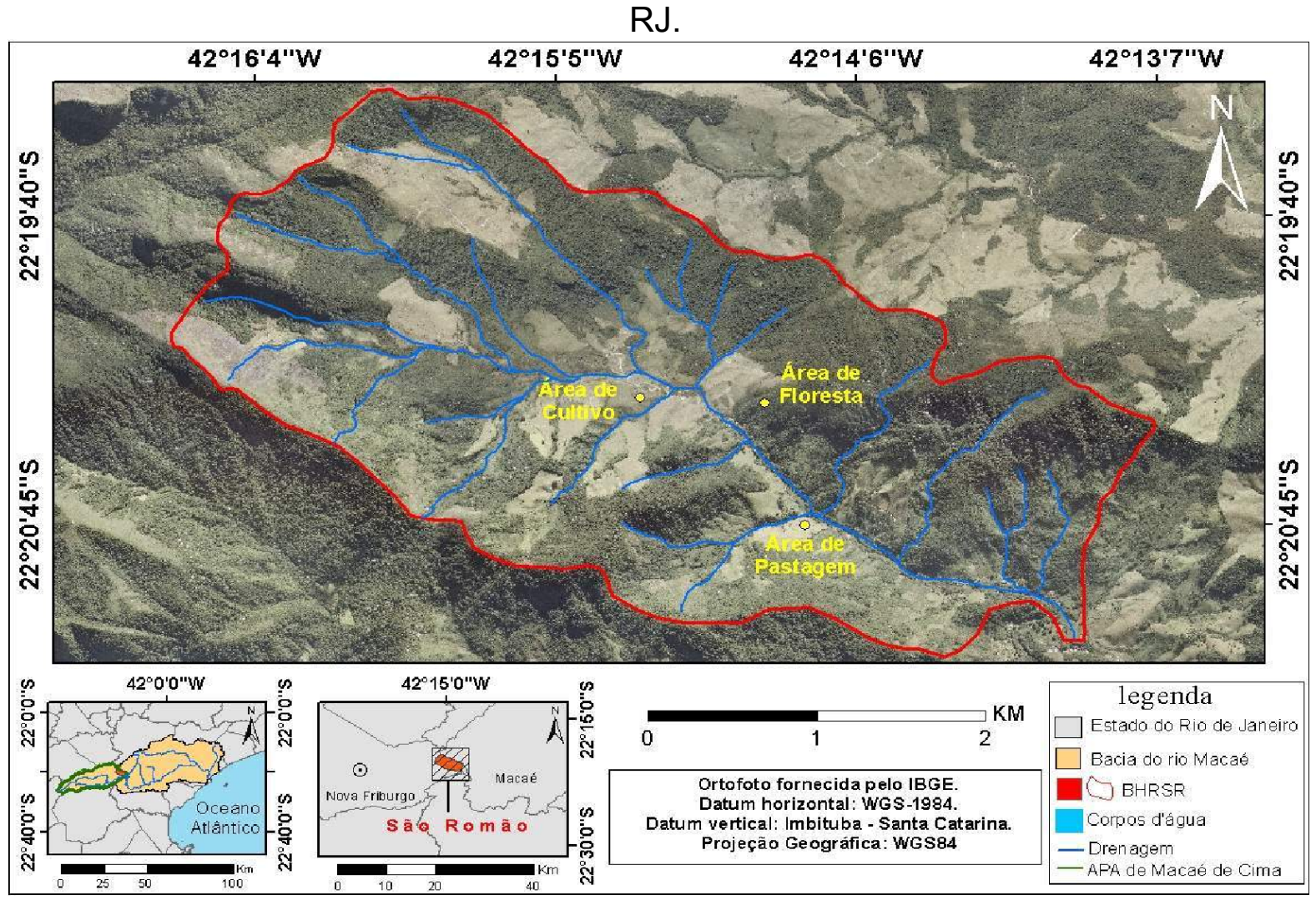

Fonte: Os autores 
Além de estar localizada num dos municípios com maior área de Mata Atlântica preservada, na região Serrana do Estado do Rio de Janeiro, essa subbacia está completamente inserida na Área de Proteção Ambiental Estadual de Macaé de Cima, cujo objetivo principal é proteger a Floresta Ombrófila Densa com sua fauna e flora inerentes bem como os mananciais das bacias que garantem não só a qualidade das águas do terço superior, mas também do terço médio e inferior de toda a bacia do rio Macaé (INEA, 2014).

Segundo Tornthwaite e Mather (1995 apud Mendes, 2010), o clima da região é do tipo A-superúmido e B-mesotérmico e é correspondente à classificação 'Cfb' conforme Koppen. A temperatura média anual é de $17,9^{\circ} \mathrm{C}$, sendo de janeiro a março os meses mais quentes e, de junho a agosto, os meses mais frios.

Estudos realizados por Nascimento et al. (2010) apontam que os regimes pluviométricos da bacia hidrográfica do rio Macaé oscilam de acordo com o relevo, onde os maiores volumes de chuva concentram-se no alto curso (lugar onde a subbacia está localizada), se comparado aos dados do médio e baixo curso. Os autores também afirmam que as grandes altitudes podem influenciar em invernos frescos e verões quentes ou brandos.

A geologia encontrada na região de Macaé de cima, segundo o projeto RADAM (1983), é marcada pela presença de rochas intrusivas e metamórficas PréCambrianas, inserida na unidade litoestatigráfica do "complexo Paraíba do Sul". A região é marcada por intensas zonas de falhamento e possíveis movimentos tangenciais sobre as falhas principais (BRASIL, 1983).

Segundo Dantas (2001), a geomorfologia da área de estudo encontra-se em relevo montanhoso e bastante acidentado, com predominância de vertentes retilíneas a côncavas, escarpadas e com topos levemente arredondados, inserida, assim, no domínio de 'Escarpas Serranas'. Essas características são um forte indicador para a grande ocorrência da erosão e de movimentos de massa nessa região, principalmente, quando associados ao manejo inadequado do uso do solo.

De acordo com a EMBRAPA (2003), o solo encontrado na sub-bacia hidrográfica do rio São Romão enquadra-se na classificação de "Cambissolos Háplicos Ta Eutróficos". Essa classe de solos representa $79 \%$ para toda a bacia do alto rio Macaé. Segundo Resende et al. (2007), esses solos são rasos e inerentes de regiões escarpadas e com alta suscetibilidade à erosão. A classificação dada pela EMBRAPA (2003) é favorável ao plantio, pois apresenta saturação de bases no solo $\left(\mathrm{Ca}_{2}{ }^{+}, \mathrm{Mg}_{2}{ }^{+}, \mathrm{K}^{+}\right.$e $\left.\mathrm{Na}^{+}\right)$e argilas com grande capacidade de troca catiônica (CTC). Também foi possível constatar em campo a presença expressiva de Neossolos Litólicos em todos os segmentos da bacia, principalmente, nas áreas de maior declividade.

Quanto à classificação da vegetação encontrada na região, há o domínio de Floresta Ombrófila Densa Montana, situada entre 500 a 1500 metros de altitude, cuja estrutura é mantida, principalmente, próxima ao cume dos relevos dissecados (INEA, 2011).

Segundo Mendes (2010), o quadro favorável de conservação da região de Macaé de Cima é fruto do seu processo histórico de ocupação. Para a autora, a bacia do rio Macaé, no século XIX e início do século XX, foi intensamente marcada pela monocultura do café que destruiu grande parte da Mata Atlântica da região. Entretanto, diferentemente do que aconteceu com os demais remanescentes de 
Mata Atlântica no Estado do Rio de Janeiro, onde o uso da floresta era substituído, também, pelo pasto, a Área de Proteção Ambiental Estadual de Macaé de Cima foi marcada majoritariamente por culturas de subsistência como, por exemplo, banana, inhame e mandioca (MENDES, 2010).

A área é ocupada predominantemente por produtores rurais, sendo atualmente os cultivos de banana, eucalipto e açaí os mais importantes. Esses usos estão atrelados, principalmente, à agricultura de subsistência, mostrando o cultivo de bananeiras e o uso de pastagens maior expressividade na paisagem (figura 2):

Figura 2: Tipos de uso na sub-bacia hidrográfica do rio São Romão

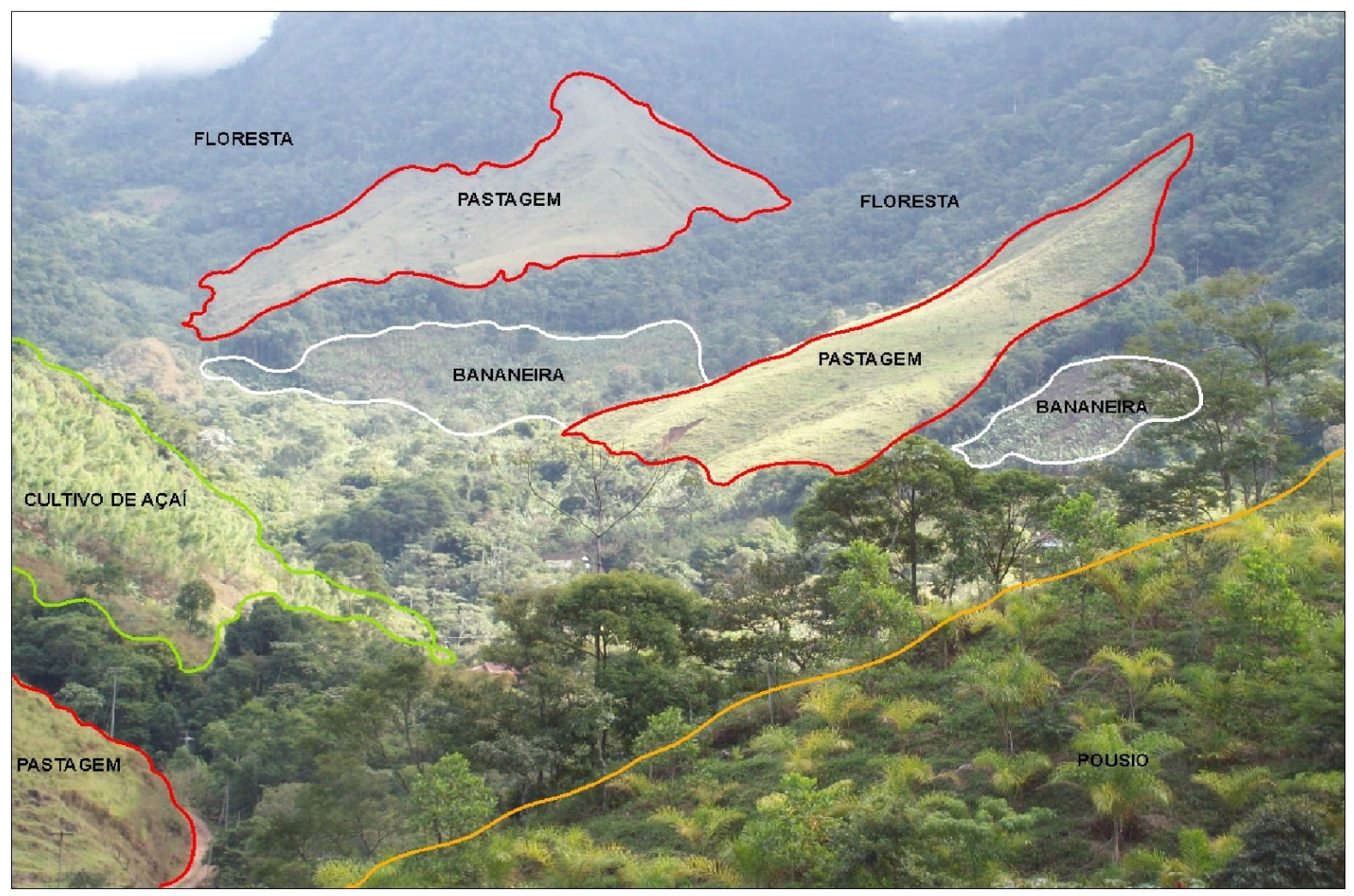

Fonte: Os autores

\section{MATERIAL E MÉTODOS}

Para atender aos objetivos dessa pesquisa, dividiu-se a metodologia em duas partes: (I) trabalho de gabinete e campo e, (II) análises em laboratório.

$\mathrm{Na}$ primeira parte, foi necessário um levantamento das informações cartográficas que viessem subsidiar a escolha da sub-bacia hidrográfica e dos pontos para a visita de campo. Para tal, utilizaram-se ortofotos do ano de 2005 (com 1 metro de resolução espacial), imagem de satélite ALOS (com 10 metros de resolução espacial), Modelo Digital de Terreno (MDT) do IBGE (na escala de 1:25.000) e arquivos no formato shapefile (do Estado do Rio de Janeiro e dos seus municípios, da APA Estadual de Macaé de Cima e da bacia hidrográfica do rio Macaé). Posteriormente, houve a vetorização da sub-bacia hidrográfica do rio São Romão e da sua rede de drenagens. 
O tratamento e extração das informações foram realizadas no software SPRING (para geração do mapa de uso do solo considerando o método de classificação supervisionada) e ArcGis 10.2 .2 para geração de layout e saída dos mapas.

Em campo, foi utilizado um GPS para confrontar com as informações previamente obtidas em gabinete na escolha das possíveis áreas (Tabela 1). Assim, três tipos de usos do solo foram selecionados (floresta, pasto e cultivo de açaí) para iniciar a coleta das amostras deformadas e indeformadas de solos. Todas as amostras foram coletadas da média para a baixa encosta de cada uso, admitindo-se o modelo discutido por Horton (1945) que previu a concentração do fluxo de água e maior erosão a partir do terço médio das encostas.

Tabela 1: Tipos de uso na sub-bacia hidrográfica do rio São Romão

\begin{tabular}{c|c|c|c|}
\hline Característica/ Usos & Floresta & Pasto & Cultivo \\
\hline \multirow{2}{*}{ Coordenadas } & $22^{\circ} 20^{\prime} 19^{\prime \prime} \mathrm{S}$ & $22^{\circ} 20^{\prime} 44^{\prime \prime} \mathrm{S}$ & $22^{\circ} 20^{\prime} 17^{\prime} \mathrm{S}$ \\
& $42^{\circ} 14^{\prime} 59^{\prime}, \mathrm{W}$ & $42^{\circ} 14^{\prime} 16^{\prime \prime} \mathrm{W}$ & $16,67^{\circ}$ \\
\hline Declividade & $30,47^{\circ}$ & $20,17^{\circ}$ & $531 \mathrm{~m}$ \\
\hline Elevação & $533 \mathrm{~m}$ & $428 \mathrm{~m}$ & Açaí \\
\hline Classificação & Ombrófila densa & $\begin{array}{c}\text { Grama-batatais } \\
\text { (Paspalum natatum) }\end{array}$ & \\
\hline
\end{tabular}

Fonte: Os autores

A floresta nativa, de classificação 'Ombrófila Densa', encontra-se preservada por um período de mais de 50 anos, segundo informações obtidas com os agricultores no local e fotos aéreas cedidas pelo IBGE, referentes à década de 1970 . O uso florestal será utilizado como referencial em termos de qualidade das propriedades físicas, químicas e biológicas do solo, quando se comparado a novos usos e manejos do solo dentro da sub-bacia hidrográfica do rio São Romão.

O cultivo de Açaí possui histórico prévio de rotação do uso da terra que varia de 4 a 6 meses, de acordo com a cultura a ser desenvolvida. Foi plantado no sentido das curvas de nível, em covas e na forma de fileiras, sem a presença de outros cultivos. Em entrevista com o dono da terra, constatou-se que existe a prática de arar e limpar o terreno com uma enxada antes de iniciar um novo plantio. Por se tratar de uma agricultura familiar, possibilita que o solo fique sob pousio por um período de 3 meses antes de iniciar um novo plantio. Foi constatado erosão do tipo laminar.

A pastagem é marcada pela presença de grama-batatais (Paspalum natatum). Segundo Pereira (2006), esse tipo de pastagem é típico de solos que apresentam média a alta fertilidade, com regime de chuvas que ultrapassa os $600 \mathrm{~mm} / \mathrm{ano}$ e temperaturas que variam de 5 a $35^{\circ} \mathrm{C}$, além de apresentarem eficácia na proteção dos solos. Embora tenha sido constatada erosão do tipo laminar, também foi possível identificar ravinas e pequenos movimentos de massa em outras encostas sob pastagens.

Nos usos identificados, realizou-se a coleta de amostras indeformadas com um amostrador volumétrico de Uhland de $100 \mathrm{~cm}^{3}$ para as análises de densidade aparente (Dap), microporosidade, macroporosidade e porosidade total. Foram realizadas, também, coletas de amostras deformadas para os ensaios de distribuição granulométrica, densidade das partículas, carbono orgânico e pH. 
$\mathrm{Na}$ segunda parte, iniciaram-se as análises de distribuição granulométrica (pelo método da pipeta), densidade aparente (pelo método do anel volumétrico), densidade das partículas (pelo método do balão volumétrico), micro e macroporosidade, e porosidade total (pelo método da mesa de tensão), carbono orgânico (por titulação, via oxidação da matéria orgânica com Dicromato de Potássio) e pH em água e em KCL (solução de KCL 1N). Ressalta-se que todos os ensaios seguiram as normas preconizadas pela EMBRAPA (2011).

\section{RESULTADOS E DISCUSSÕES}

\subsection{Uso do solo}

A distribuição dos usos na sub-bacia hidrográfica do rio São Romão aponta um cenário favorável para a preservação da floresta, no controle da erosão e maior tempo de permanência da água no solo (dependendo da intensidade da chuva), diante dos altos índices pluviométricos encontrados da região, favorecidos principalmente, pela ocorrência de chuvas orográficas na Serra do Mar.

O mapa de uso do solo (figura 3) mostra que a Floresta Ombrófila Densa, em estágio avançado de regeneração, encontra-se preservada majoritariamente à montante da sub-bacia hidrográfica no sentido noroeste-sudeste, devido à dificuldade de ocupação e uso nessas áreas pelas altas declividades inerentes do modelado. Logo, a geomorfologia favorece os usos sob as atividades antrópicas no sentido que varia de sul até oeste da sub-bacia hidrográfica do rio São Romão.

Nota-se, portanto, que os estágios iniciais e intermediários de regeneração florestal foram possivelmente desmatados no passado pela facilidade e inserção da agricultura familiar de subsistência, onde a ocupação na parte sul, sudoeste e oeste da sub-bacia foi favorecida por apresentar encostas mais suavizadas e solos mais profundos, quando se comparado à parte vai de sudeste até noroeste da sub-bacia, em direção à montante.

A constatação das análises qualitativas e quantitativas relacionada ao mapa de uso do solo pode ser visualizada na figura 3 e tabela 2, com a distribuição dos usos e suas respectivas áreas correspondentes ao total de área ocupada na subbacia hidrográfica do rio São Romão. 
Figura 3: Mapa de uso do solo da sub-bacia hidrográfica do rio São Romão

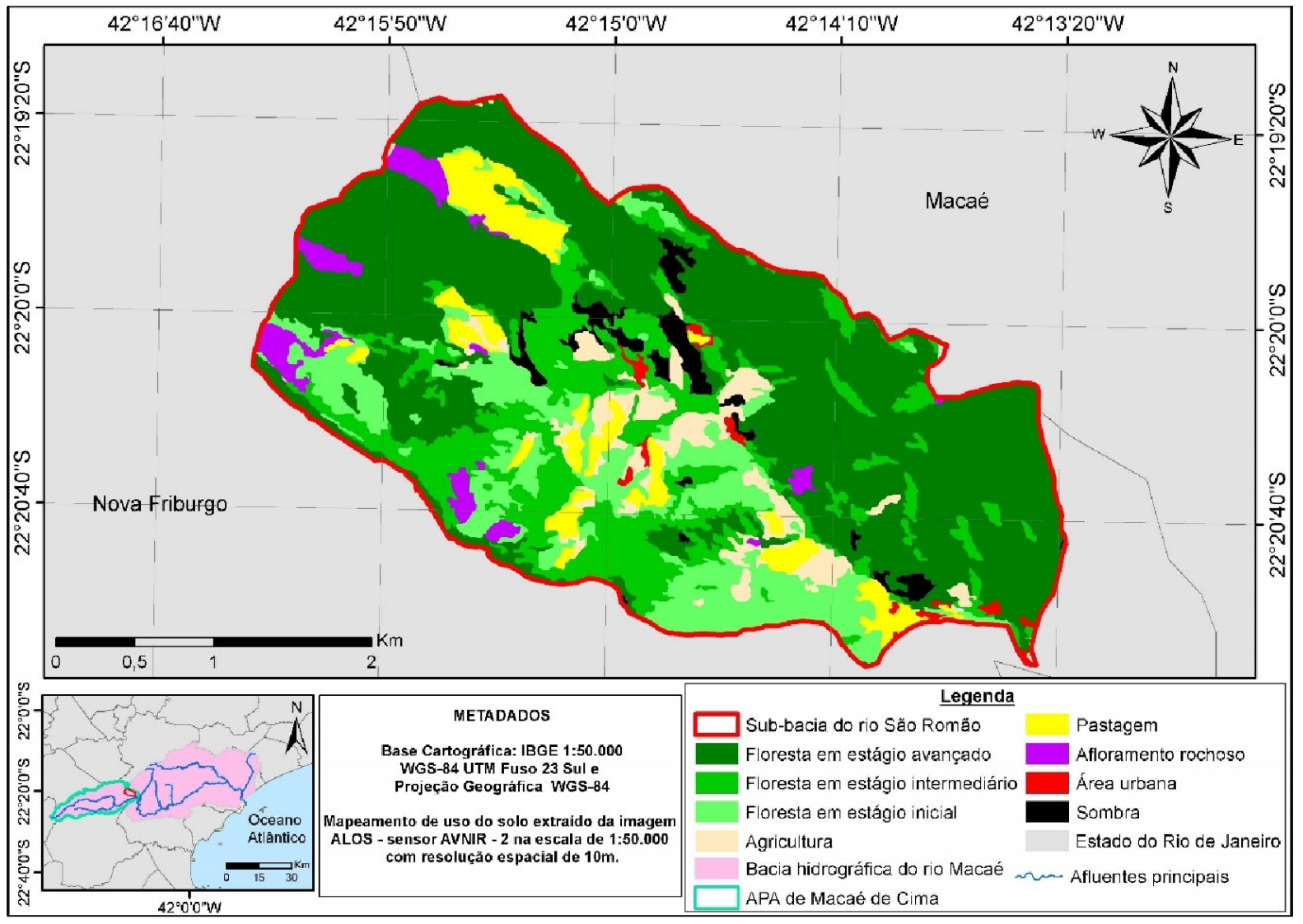

Fonte: Os autores.

Tabela 2: Distribuição dos usos da sub-bacia por área e sua porcentagem equivalente

\begin{tabular}{|c|c|c|}
\hline Classes de cobertura & ha & $\%$ \\
\hline Afloramento rochoso & 38 & 1,8 \\
\hline Agricultura & 133 & 6,3 \\
\hline Área urbana & 28 & 1,4 \\
\hline Pastagem & 118 & 5,5 \\
\hline Sombra & 138 & 6,6 \\
\hline Vegetação em estágio avançado & 961 & 45,2 \\
\hline Vegetação em estágio intermediário & 385 & 18,1 \\
\hline Vegetação em estágio inicial & 321 & 15,1 \\
\hline Total & 2120 & 100 \\
\hline
\end{tabular}

Fonte: Os autores.

Embora a soma da área florestada represente $78,4 \%$ da área da sub-bacia, a diferença dos estágios sucessionais de regeneração da vegetação mostra que a soma do estágio inicial e intermediário totaliza $33,2 \%$, indicando que estes podem 
estar mais vulneráveis às novas pressões das atividades antrópicas, como o avanço da agricultura, pastagem e da área urbana, que somam $13,2 \%$ da área total.

As atividades agropastoris representam $11,8 \%$ da área total da sub-bacia, sendo que as áreas com características urbanas ocupam 1,4\%. Os dados mostram que a sub-bacia é ocupada por pequenos agricultores e confirma a historicidade da agricultura familiar, com forte recuperação da vegetação frente a essas atividades.

De acordo com o INEA (2012), o alto curso da bacia do rio Macaé, que é caracterizada pela APA Estadual de Macaé de Cima, apresenta 83,44\% de área preservada pela floresta Ombrófila Densa Montana, seguido de $12,57 \%$ do uso da pastagem e $1,75 \%$ de ocupação urbana de média intensidade. Os demais $2,24 \%$ de área restringem-se ao uso da agricultura e da floresta Ombrófila Densa Alto Montana.

Os resultados de uso do solo apontados pelo INEA (2012) certamente influenciam nos resultados de monitoramento da qualidade das águas realizado por Pinheiro et al. (2008), onde constatou que o alto curso apresentou índice de qualidade da água favorável para o consumo. Tal relação ocorre pelo fato das florestas apresentarem as maiores taxas de infiltração e menor coeficiente de escoamento superficial em relação aos demais usos, quando se considera a textura do solo e as declividades similares (COELHO NETTO, 2009), pois tais processos resultam em um menor índice de turbidez e alteração química das águas por contaminação.

Nessa perspectiva, as informações apresentadas na figura 3 e na tabela 2 permitem concluir que o cenário da sub-bacia hidrográfica do rio São Romão contribui para a preservação da floresta Ombrófila Densa Montana e Alto Montana, admitindo-se o uso da pastagem e da agricultura como uma ameaça ao desequilíbrio ambiental para toda a bacia do rio Macaé, que visa aos benefícios da própria floresta na preservação dos solos, na qualidade das águas e até mesmo a atração turística para a região.

Embora a sub-bacia esteja preservada, as marcas de erosão na paisagem (figura 4 A e B) mostram que a forma de manejo realizada na sub-bacia hidrográfica do rio São Romão, associada às características topográficas e a erodibilidade, pode potencializar a perda de solos e o desequilíbrio ambiental em toda a bacia hidrográfica do rio Macaé. 
Figura 4: (A) Erosão dos solos no uso da pastagem e, (B) no cultivo de açaí sob pousio

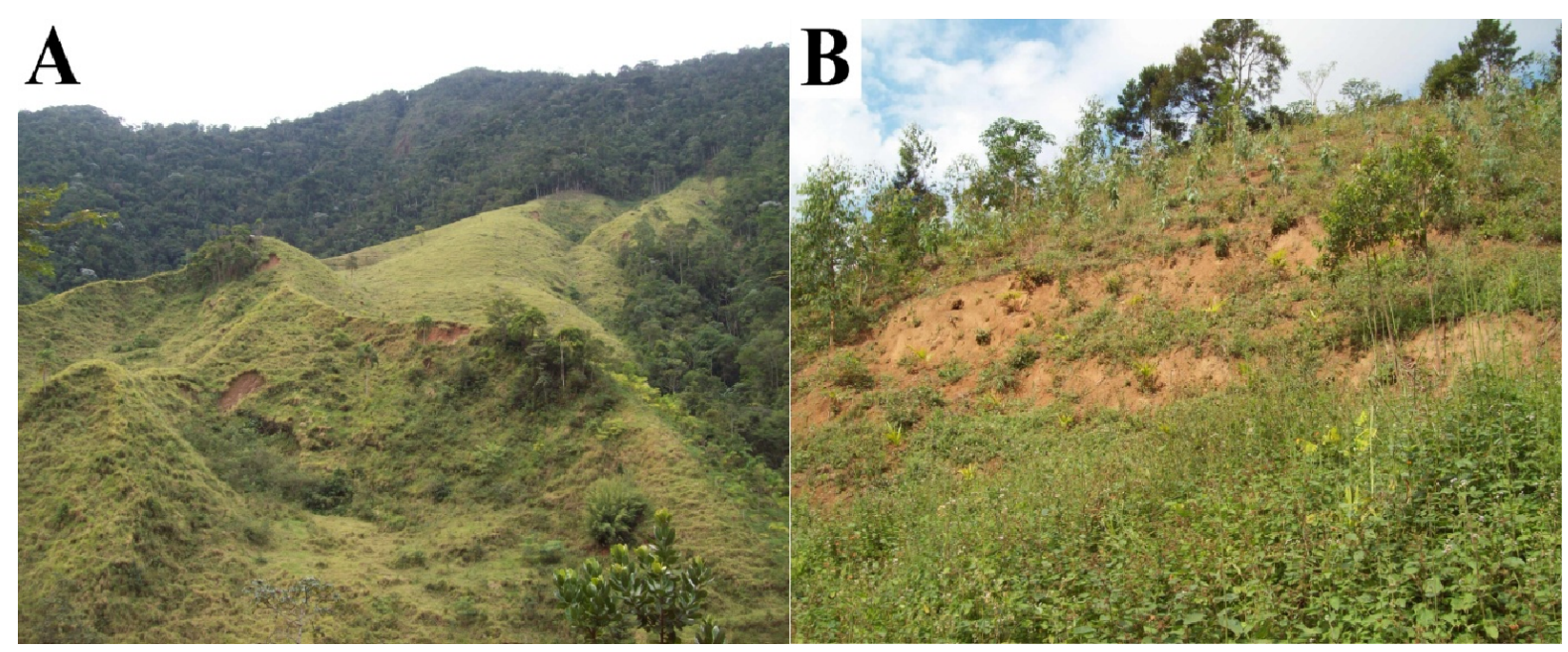

Fonte: Os autores (2018)

\subsection{Análise Granulométrica}

A partir das análises realizadas em campo e laboratório, pode-se dizer que todos os usos e profundidades apresentaram classificação franco-arenosa, com exceção do uso da floresta, na profundidade de $10-20 \mathrm{~cm}$, que apresenta classificação granulométrica franco-siltoso (Tabela 3):

Tabela 3: Classificação granulométrica dos horizontes superficiais, de acordo com o Sistema Brasileiro de Classificação de Solos (EMBRAPA, 2013)

\begin{tabular}{|c|c|c|c|c|c|c|c}
\hline \multirow{2}{*}{$\begin{array}{c}\text { Usos do } \\
\text { solo }\end{array}$} & $\begin{array}{c}\text { Prof. } \\
(\mathrm{cm})\end{array}$ & $\begin{array}{c}\text { Areia } \\
\text { grossa }\end{array}$ & $\begin{array}{c}\text { Areia } \\
\text { fina }\end{array}$ & $\begin{array}{c}\text { Areia } \\
\text { total }\end{array}$ & Silte & Argila & \multirow{2}{*}{$\begin{array}{c}\text { Classificação } \\
\text { textural }\end{array}$} \\
\hline Floresta & $0-10$ & 442 & 196,6 & 638 & 253,8 & 190 & Franco arenoso \\
\hline Floresta & $10-20$ & 240,3 & 113,8 & 354,1 & 615,9 & 129 & Franco siltoso \\
\hline & & & & & & & \\
\hline Pasto & $0-10$ & 544,3 & 125,3 & 669,6 & 259,5 & 124 & Franco arenoso \\
\hline Pasto & $10-20$ & 426,4 & 147,2 & 600,6 & 215,7 & 187 & Franco arenoso \\
\hline & & & & & & & \\
\hline Cultivo & $0-10$ & 420,2 & 165,4 & 585,6 & 343 & 128 & Franco arenoso \\
\hline Cultivo & $10-20$ & 463,2 & 171,1 & 634,5 & 301,7 & 121 & Franco arenoso \\
\hline
\end{tabular}

Fonte: Os autores

Segundo Medina (1972) e Brady (1989), a textura dos solos é um dos fatores que menos variam no tempo e, por isso, é considerada como propriedade básica nos estudos que envolvem a degradação dos solos e sua relação com os aspectos edáficos, sendo essa propriedade determinadora, por exemplo, da quantidade de areia, silte e argila.

Guerra (2009, p. 155), salienta que "a textura afeta a erosão, porque algumas frações granulométricas são removidas mais facilmente do que outras" e que o silte e a areia fina, por exemplo, são as mais propensas a serem erodidas, ao contrário 
da areia grossa e dos argilominerais, que possuem maior peso e coesão, respectivamente (GUERRA e BOTELHO, 1996).

Entretanto, ainda que a análise granulométrica tenha apenas a função de quantificar o tamanho dos grãos encontrados nas amostragens desejadas e, sendo a tipologia dos minerais encontrados nessas frações determinantes para uma maior ou menor coesão da formação de agregados, esse tipo de análise também possibilita inferências das formas de manejo encontradas nas encostas.

A partir dos resultados apresentados na tabela 3 compreende-se que esses solos podem estar sofrendo intensa lixiviação, cujas partículas mais finas (silte e argila) são carregadas para jusante das encostas pelo escoamento superficial, o que possibilita a permanência de partículas mais grosseiras, além da topografia atuar como facilitador do processo erosivo.

Os altos valores de areia grossa apresentados permitem inferir que esses solos possuem boa drenagem no perfil, mas que podem sofrer restrições se compactados, pois leva ao aumento da erosão através do destaque, transporte e deposição dos materiais para a base das encostas, e favorece o processo de assoreamento dos rios não só para a sub-bacia estudada, como também pode contribuir para o processo de degradação do terço médio e inferior da bacia do rio Macaé.

Segundo Reichardt (1987), os solos apresentados para este estudo conferem altas taxas de infiltração sobre densidade aparente baixa, com frentes de molhamento em forma mais vertical do que horizontal devido à energia gravitacional quando comparado aos solos argilosos.

Embora a distribuição granulométrica tenha pouca variabilidade no espaçotempo, por meio de processos intempéricos, ela pode ser altamente modificada num curto espaço de tempo pela erosão, quando submetida a usos e formas de manejo que favoreçam as alterações físicas desses solos. Entretanto, tratando-se da importância da granulometria de forma isolada, pode-se concluir que solos arenosos são altamente favoráveis para a recarga de aquíferos confinados, maior reserva de água nas bacias hidrográficas e redução do escoamento superficial (runoff), devido ao maior tempo em que a água permanece no sistema quando submetidos a regimes pluviométricos altos.

\subsection{Densidade aparente e densidade das partículas}

Os dados de Densidade Aparente (Dap) e Densidade das partículas ( $D p)$ são fundamentais na avaliação da compactação dos solos e possibilita inferências quanto à mineralogia e à porosidade do solo, respectivamente, sendo importante variável para as condições de manejo do uso do solo (BETONI e LOMBARDI NETO, 2010).

De acordo com os parâmetros de qualidade dos solos discutidos na literatura, segue abaixo (Tabela 4) os dados de densidade para cada uso do solo e profundidade. 
Tabela 4: Valores de Densidade Aparente (Dap) e das partículas (Dp) nas profundidades de 0-10 e 10-20 cm em relação aos usos do solo

\begin{tabular}{|c|c|c|c|c|c|c|}
\hline Uso do solo & \multicolumn{2}{|c|}{ Floresta } & \multicolumn{2}{c|}{ Pasto } & \multicolumn{2}{c|}{ Cultivo } \\
\hline Profundidade & $0-10 \mathrm{~cm}$ & $10-20 \mathrm{~cm}$ & $0-10 \mathrm{~cm}$ & $10-20 \mathrm{~cm}$ & $0-10 \mathrm{~cm}$ & $10-20 \mathrm{~cm}$ \\
\hline $\operatorname{Dap}\left(\mathrm{Kg} / \mathrm{dm}^{3}\right)$ & 1,02 & 1,10 & 1,51 & 1,52 & 1,14 & 1,30 \\
\hline $\mathrm{Dp}\left(\mathrm{Kg} / \mathrm{dm}^{3}\right)$ & 2,64 & 2,67 & $\begin{array}{c}2,59 \\
\text { Fonte: Os autores }\end{array}$ & 2,58 & 2,55 & 2,56
\end{tabular}

Segundo Kiehl (1979), os valores da densidade aparente em solos minerais oscilam de 1,1 a 1,6 Kg.dm ${ }^{-3}$. Já em solos orgânicos, os valores variam de 0,6 a 0,8 $\mathrm{Kg}_{\mathrm{dm}}{ }^{-3}$, principalmente, pela presença de raízes e restos de animais. Entretanto, 0 autor também apresenta faixa de Dap de 1,25 a 1,40 Kg.dm ${ }^{-3}$ para solos arenosos. A porosidade total dos solos varia de 40 a $60 \%$, cuja densidade real média fica em torno de 2,65 Kg.dm³. Já Guerra (1990) aponta valores mínimos de densidade aparente abaixo de 1,3 Kg.dm ${ }^{-3}$ e valores altos acima de $1,6 \mathrm{Kg} \cdot \mathrm{dm}^{-3}$.

Os dados de Dap sob o uso florestal, nas duas profundidades, ficaram em torno de um pouco mais de $1,0 \mathrm{Kg}_{\mathrm{dm}}{ }^{-3}$, o que indica porosidade ideal para 0 equilíbrio do sistema trifásico (água, ar, material mineral) nos solos, resultado que confirma a possibilidade de drenagem satisfatória no perfil e a importância da floresta no balanço hídrico da sub-bacia hidrográfica do rio São Romão e, também, em relação a toda bacia hidrográfica do rio Macaé.

O uso do solo sob pastagem apresentou os maiores valores de Dap, já que ficou em torno de um pouco mais de $1,5 \mathrm{Kg}_{\mathrm{dm}}{ }^{-3}$. Tal motivo pode ser explicado pelo pisoteio do gado (pecuária extensiva) que acaba compactando a superfície dos solos e diminui o volume de poros, comparando-se com a floresta, onde geralmente apresenta Dap significativamente mais baixa pelo maior aporte de matéria orgânica e ação das raízes (BRADY, 1989).

Estudo apresentado por Loureiro et al. (2011), numa sub-bacia localizada no terço médio da bacia do rio Macaé, mostra uma média de densidade aparente em torno de $1,5 \mathrm{Kg} \mathrm{dm}^{-3}$ para solos franco-argilo-arenosos em uso de pastagem. Destaca, ainda, que os altos valores são resultados do manejo e foram fundamentais para deflagrar a formação de voçorocas e a mudança expressiva da paisagem.

A área de cultivo de açaí apresentou valores intermediários entre os usos observados. Tais resultados podem estar atrelados à rotação de culturas que varia em média de 3 a 4 meses. Além disso, o dono da terra costuma limpar e arar a superfície do solo com enxada, o que aumenta a erosão dos solos quando esses estão desprovidos de vegetação porque leva ao rompimento dos agregados da superfície do solo. Tal prática também aumenta um pouco a densidade aparente na profundidade de 10-20, pois o uso da enxada compacta na aração. Assim, a profundidade de 0-10 cm apresenta densidade aparente próximo a 1,14 $\mathrm{Kg}_{\mathrm{dm}} \mathrm{dm}^{-3}$, enquanto na profundidade de $10-20 \mathrm{~cm}$ a Dap fica em torno de $1,3 \mathrm{Kg} \cdot \mathrm{dm}^{-3}$.

Embora os valores de densidade aparente estejam próximos do encontrado para o uso florestal, as formas de manejo são diferentes. No caso da floresta, há uma Dap influenciada pelo sistema radicular intenso devido à fauna endopedônica e ao aporte de matéria orgânica. Já na área cultivada, a Dap sofreu ação induzida pelo preparo da terra, e que ao desprotegê-la, pode acarretar o início de processos 
erosivos que podem evoluir para ravinas e voçorocas como já mostradas anteriormente na figura 4.

Quanto aos dados de densidade das partículas (Tabela 4), compreendem-se, segundo Vargas e Nunes (1992), que os resultados adquiridos se encontram na faixa dos minerais silicatados mais comuns encontrados em rochas granitognáissicas como: o feldspato - $\mathrm{K}$ - com densidade de $2,57 \mathrm{Kg} \mathrm{dm}^{-3}$; caulinita - com densidade de 2,60 Kg.dm ${ }^{-3}$; e o quartzo - com densidade de 2,65 $\mathrm{Kg}_{\text {. } \mathrm{dm}^{-3}}$. Tais resultados são importantes, pois são usados para calcular o volume de sólidos das amostras, para inferir sobre a mineralogia presente na granulometria e sua relação com outras propriedades físicas (como na formação de macroagregados) e químicas (capacidade de troca catiônica - CTC) dos solos.

A densidade das partículas do uso florestal nas duas profundidades apresentou os maiores valores, um pouco acima de 2,60 Kg.dm${ }^{-3}$ e 2,65 $\mathrm{Kg}^{-\mathrm{dm}^{-3}}$, respectivamente. Isso pode ser explicado pela localização do ponto ao qual foram realizadas as coletas, no caso, em encosta muito íngreme, com aproximadamente 25 à $30^{\circ}$ de declividade, com associações de solos que variam de Neossolos Litólicos à Cambissolos e com maior influência do horizonte $C$ devido à ocorrência de solos mais jovens. Assim, os valores de densidade das partículas indicam mineralogia do tipo quartzosa derivado da formação granítica do complexo Paraíba do Sul (BRASIL, 1983) e convergente aos resultados granulométricos apresentados na tabela 3.

Já no uso do solo sob pastagem e no cultivo de açaí, a densidade das partículas apresenta valores menores do que no uso florestal, pois resultam na predominância de argilominerais do tipo caulinita e feldspato-K. Logo, acredita-se que a declividade esteja influenciando em tais valores, ao proporcionar a formação de solos mais profundos e, portanto, mais desenvolvidos do que no uso florestal.

\subsection{Microporosidade, Macroporosidade e Porosidade Total}

Segundo Kiehl (1979) e Brady (1989), a porosidade é fundamental para as trocas gasosas que ocorrem na atmosfera do solo pela fauna endopedônica e pelas raízes, além de possibilitar maior infiltração e percolação da água. Estas são fundamentais para o controle da erosão em áreas com alta pluviosidade, haja vista que possibilitam a chegada de um menor volume de água no canal principal, se consideradas bacias hidrográficas que apresentam tendência à forma circular - 0 que ocasiona não somente num maior tempo de permanência da água no sistema, mas também na diminuição de sedimentos nas calhas fluviais.

Embora o conhecimento da porosidade total do solo seja relevante, não mostra a sua distribuição na amostragem (KIEHL, 1979), que deve ser caracterizada pelas micro e macroporosidade, pois regulam as entradas e saídas de água no solo (BRADY, 1989), e que são fundamentais para compreensão do início ao processo erosivo.

Nessa perspectiva, o uso e o manejo do solo são essenciais no controle da porosidade. Os dados apresentados nas figuras 6 e 7 mostram-se coerentes com os dados de densidade apresentados na tabela 4, mostrando o uso florestal com os maiores valores de macroporosidade e a pastagem com os maiores valores de microporosidade, nas profundidades de 0-10 e 10-20 cm. 
Influência do manejo...

Figura 6: Distribuição da micro e macroporosidade na profundidade de 0-10 $\mathrm{cm}$.

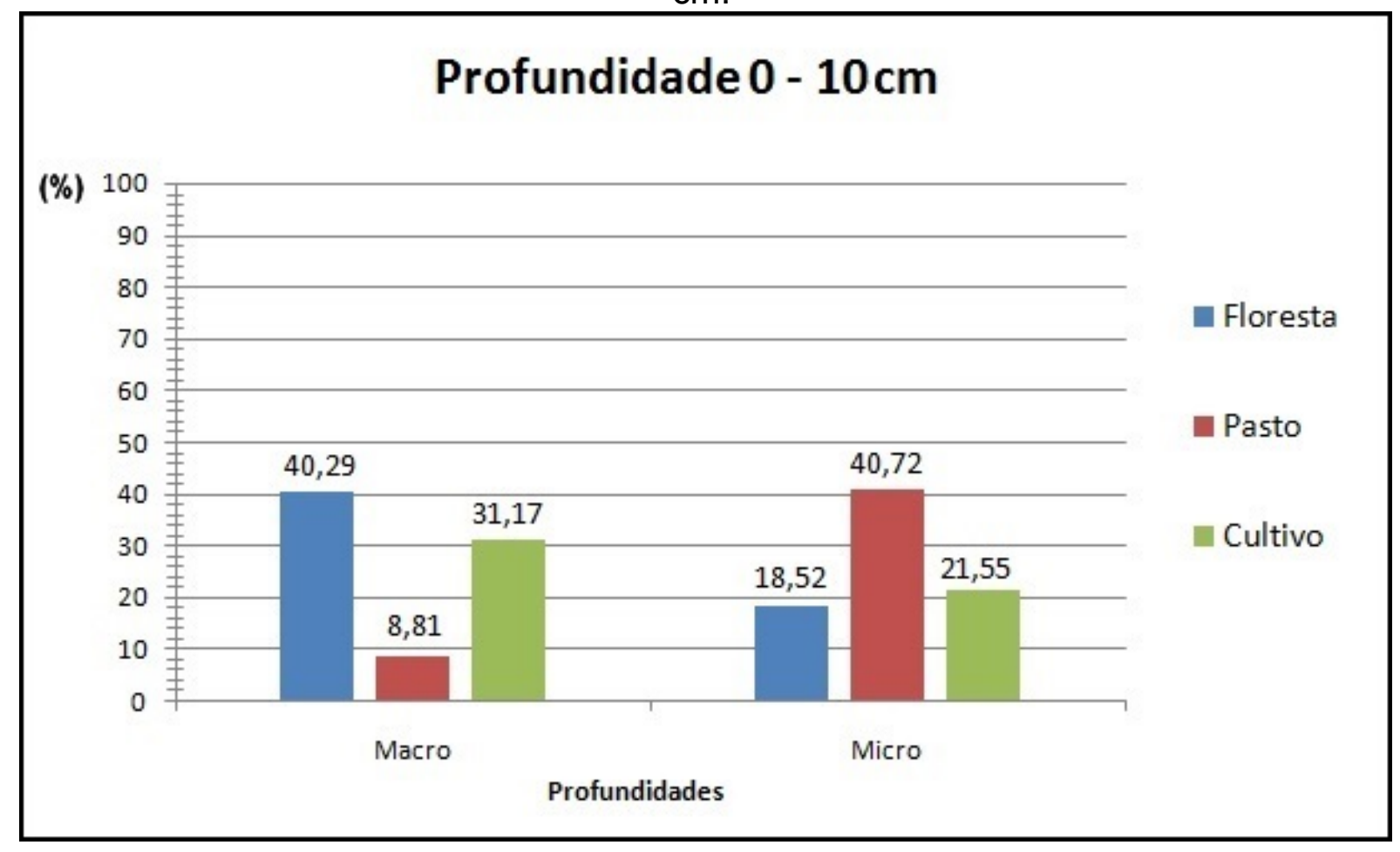

Fonte: Os autores (2018).

Figura 7: Distribuição da micro e macroporosidade na profundidade de 10-20 $\mathrm{cm}$.

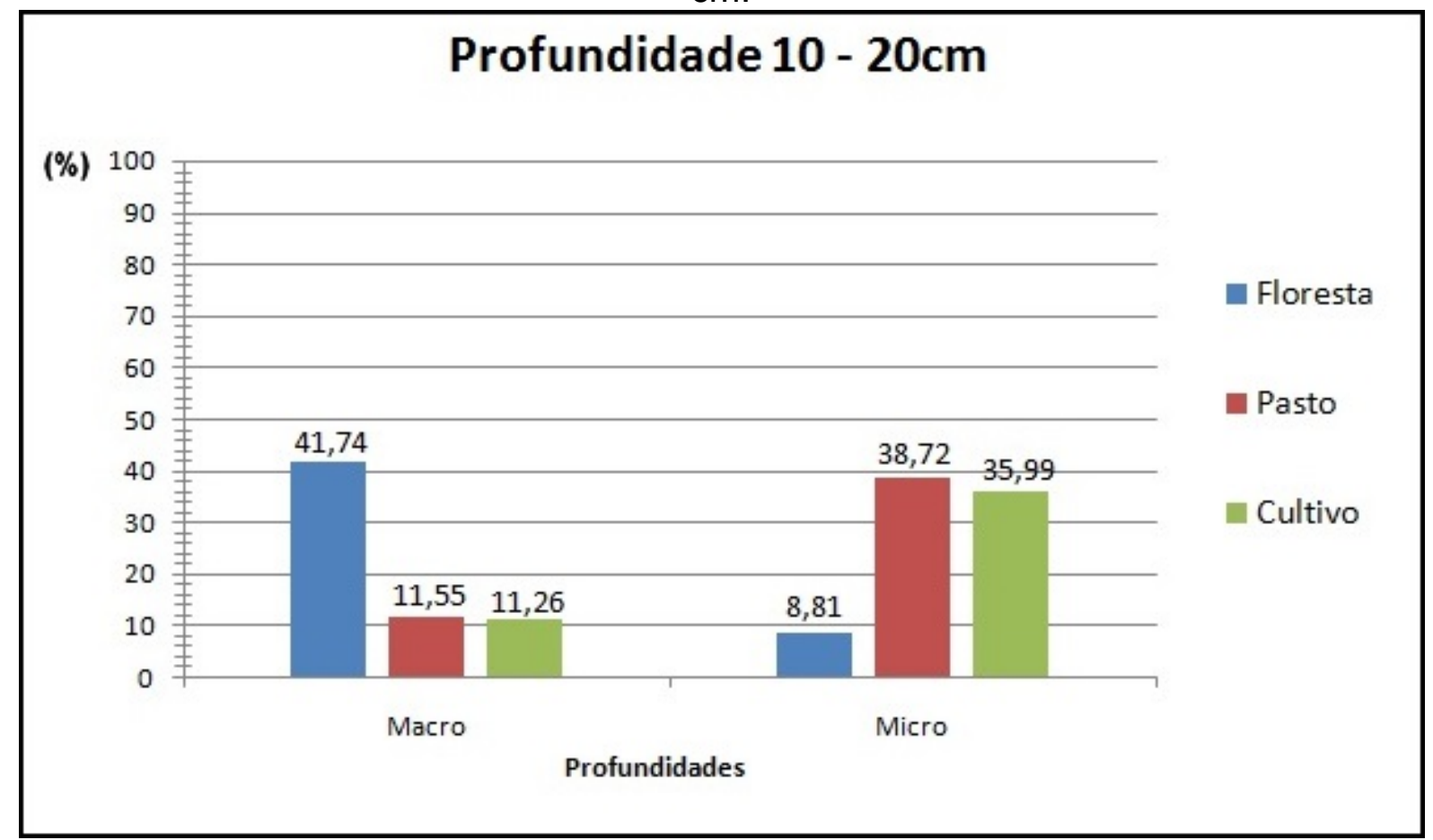

Fonte: Os autores (2018).

No uso florestal, sobre profundidade de $0-10 \mathrm{~cm}$, a porosidade total foi de $58,81 \%$, a macroporosidade com $40,29 \%$ e a micro $18,52 \%$. Já na profundidade de $10-20 \mathrm{~cm}$, a porosidade total foi de $50,55 \%$, a macroporosidade com $41,74 \%$ e a Estudos Geográficos, Rio Claro, 15(2): p-p, jul./dez. 2017 (ISSN 1678-698X)

http://www.periodicos.rc.biblioteca.unesp.br/index.php/estgeo 
micro $8,81 \%$. Notam-se, portanto, valores altos de porosidade nas duas profundidades, com um aumento de $1,45 \%$ da macroporosidade na profundidade de $10-20 \mathrm{~cm}$. Já para a microporosidade, houve uma redução de $9,71 \%$. Tal comportamento se explica pela presença significativa de raízes encontradas que fazem o aumento da macroporosidade desses solos e, consequentemente, a infiltração da água. O fato de a microporosidade se apresentar alta em relação à profundidade de $10-20 \mathrm{~cm}$ pode ser explicado pelas coletas terem sido realizadas próximo ao uso da pastagem, que pode influenciar no efeito de borda com a redução da umidade, aumento da luminosidade e espaçamento arbóreo.

No uso da pastagem, sobre profundidade de $0-10 \mathrm{~cm}$, a porosidade total foi de $50,27 \%$, a macroporosidade com $8,81 \%$ e a micro $40,72 \%$. Já na profundidade de $10-20 \mathrm{~cm}$ a porosidade total foi de $50,55 \%$, a macroporosidade com $11,55 \%$ e a micro $38,72 \%$. Tais resultados refletem numa compactação elevada do solo pelo pisoteio do gado na profundidade de $0-10 \mathrm{~cm}$ e, portanto, apresentando, também, os maiores valores de densidade $\left(1,5 \mathrm{Kg}^{-\mathrm{dm}^{-3}}\right)$ como já discutidos no item anterior.

No cultivo de açaí, sobre profundidade de $0-10 \mathrm{~cm}$, a porosidade total foi de $52,72 \%$, a macroporosidade com $31,17 \%$ e a micro $21,55 \%$. Já na profundidade de $10-20 \mathrm{~cm}$ a porosidade total foi de $50,55 \%$, a macroporosidade com $11,26 \%$ e a micro 35,99\%. A elevada macroporosidade na profundidade de 0-10 reflete a aragem superficial do solo com enxada pelo dono da terra, que foi reduzida drasticamente na profundidade de $10-20 \mathrm{~cm}$ devido à perda da influência do revolvimento do solo. Tais valores são proporcionais aos valores de densidade aparente, pois apresenta 1,1 Kg.dm ${ }^{-3}$ e 1,4 Kg.dm ${ }^{3}$, respectivamente (tabela 3).

Santos et al. (2010) constatou uma redução significativa das porosidades do solo quando compararam a mata com a pastagem degradada e a interação da lavoura com a pecuária. Carneiro et al. (2009) concluiu que o uso/manejo acaba por diminuir a macroporosidade em função do aumento da densidade do solo, o que possibilita o início do processo com a erosão laminar e sua evolução para ravinas e voçorocas (GUERRA, 1996; 2006).

Em resumo, a porosidade total dos solos diminuiu de acordo com a profundidade, com a exceção da pastagem, que sofre mais com a compactação do gado na profundidade de $0-10 \mathrm{~cm}$. Além disso, conclui-se que para este tipo de análise, o uso da floresta foi o que mais se aproximou do modelo de estrutura ideal do solo proposto por Kiehl (1979) e que as demais formas de uso e manejo dos solos influenciaram, significativamente, na distribuição dos poros nas profundidades avaliadas.

\subsection{Carbono orgânico e ph}

De acordo com Brady (1989) e Bayer e Mielniczuk (2002), a elevada concentração de matéria orgânica nos horizontes superficiais é extremamente benéfica para a agregação dos solos, pois diminui a erodibilidade e aumenta, significativamente, sua resistência contra a erosão (GUERRA, 1990). Nessa perspectiva, a decomposição da matéria orgânica e a lixiviação nos solos resultam em altas concentrações de íons $\mathrm{H}^{+}$, (baixo valor do potencial hidrogeniônico / pH) que também corrobora para a própria degradação da matéria orgânica no solo em meio ácido. 
A seguir (tabela 5), são apresentadas as concentrações de carbono orgânico e pH para cada uso e profundidade conforme o método preconizado pela EMBRAPA (2013).

Tabela 5: Resultado das análises de Carbono Orgânico (CO), pH em água e solução KCL, nas profundidades de $0-10 \mathrm{~cm}$ e $10-20 \mathrm{~cm}$

\begin{tabular}{|lccccccc|}
\hline Uso & \multicolumn{2}{c}{ Floresta } & \multicolumn{2}{c|}{ Pasto } & \multicolumn{2}{c|}{ Cultivo } \\
Profundidade & $\underline{0-10 \mathrm{~cm}}$ & $\underline{10-20 \mathrm{~cm}}$ & $\underline{0-10 \mathrm{~cm}}$ & $\underline{10-20 \mathrm{~cm}}$ & $\underline{0-10 \mathrm{~cm}}$ & $\underline{10-20 \mathrm{~cm}}$ \\
\cline { 2 - 3 }$(\mathrm{g} / \mathrm{Kg})$ & 53,3 & 47,92 & 49,3 & 35,68 & 43,96 & 24,65 \\
$\mathrm{pH} \mathrm{H} \mathrm{H}_{2} \mathrm{O}$ & 5,05 & 4,83 & 5,41 & 5,3 & 4,84 & 4,99 \\
$\mathrm{pH} \mathrm{KCL}$ & 4,14 & 4,14 & 4,52 & 4,64 & 4,22 & 4,04 \\
\hline
\end{tabular}

Fonte: Os autores

Ao observar os dados apresentados na tabela 5 , pode-se afirmar que os altos valores de carbono orgânico encontrados em todos os usos e profundidades se apresentam coerentes com a baixa densidade aparente (Dap) dos usos e maior porosidade total na floresta, seguido do cultivo de açaí e da pastagem, na profundidade de $0-10 \mathrm{~cm}$.

Os dados mostram que mesmo a pastagem apresentando altos valores de $\mathrm{CO}$, nas duas profundidades, foi o uso do solo que apresentou maior compactação, resultado que reafirma a influência do uso e do manejo na qualidade da sua estrutura frente aos processos erosivos, de modo que o $\mathrm{CO}$, neste caso, corrobora para diminuir a sua erodibilidade, mas não reflete diretamente em menor compactação. Além disso, admite-se que os valores de carbono orgânico apresentados para o uso da pastagem estejam associados diretamente ao esterco do gado e à presença de gramíneas.

No cultivo de açaí, o CO apresenta redução quase que pela metade quando avaliadas ambas as profundidades. Embora o cultivo de açaí apresente valores altos, a justificativa para apresentar o menor teor de $\mathrm{CO}$ em relação aos demais usos está atrelado à limpeza da terra antes de iniciar um novo período de plantio, já que se esperava maior teor de $\mathrm{CO}$ na profundidade de $10-20 \mathrm{~cm}$ e não na profundidade de $0-10 \mathrm{~cm}$, estando a aragem do solo também influenciando na profundidade de $10-20 \mathrm{~cm}$.

Os resultados permitem concluir que mesmo o solo sob pastagem estar mais compactado que os demais usos e o cultivo de açaí estejam submetidos à aragem e à limpeza superficial do solo, ambos apresentam valores altos de carbono orgânico, o que caracteriza, sob o ponto de vista biológico da degradação da matéria orgânica, um índice favorável no controle da erosão em todos os usos apresentados.

Santos e Guerra (2015) ao avaliar a influência da estrutura florestal nas propriedades físico-químicas do solo numa sub-bacia localizada terço superior do rio Macaé apresentaram valores de CO que variam de $24,5 \mathrm{~g} \cdot \mathrm{Kg}^{-1}$ a $65,9 \mathrm{~g} \cdot \mathrm{Kg}^{-1}$ no inverno e 33,1 g. Kg ${ }^{-1}$ a 78,8 g. $\mathrm{Kg}^{-1}$ no verão, já Kiehl (1979) indica 50 g. $\mathrm{Kg}^{-1}$ valor ideal para boa estruturação dos solos.

De acordo com Guerra (1990), a concentração de CO em solos arenosos (tabela 2) torna-se fundamental para a formação de agregados, haja vista a baixa 
capacidade de troca catiônica (CTC) inerente das areias, majoritariamente, compostas pela mineralogia quartzosa. Embora os usos apresentem baixa porcentagem de silte e argila (com exceção do uso florestal na profundidade de 10$20 \mathrm{~cm}$ ), as partículas estão condicionadas ao transporte por arraste sob declividades acentuadas e que pode aumentar o escoamento superficial quando submetido aos altos volumes e intensidades de chuva inerentes da região.

Um fator que pode estar ajudando a influenciar nos altos teores de carbono orgânico encontra-se relacionado com o pH dos solos avaliados. Isso, quando submetidos a altas temperaturas e regime pluviométrico favorável, como apontado por Nascimento et al. (2010) para a bacia hidrográfica do rio Macaé, pois ajuda a degradar a matéria orgânica humificada que, segundo Grosbellet et al. (2011) é fundamental para a formação de macroagregados e maior resistência dos solos à erosão.

Associam-se às altas concentrações de $\mathrm{CO}$ o volume de serrapilheira e a fauna endopedônica na área florestal, ao constante despejo de esterco bovino nas áreas de pasto e aos restos de cultura no uso agrícola, mesmo que submetido à limpeza e aragem do horizonte superficial, tornando esse quadro também extremamente favorável para formação de solos ácidos (BRADY, 1989, BAYER e MIELNICZUC, 2008)

Os valores apresentados na tabela 5 mostram que os $\mathrm{pH}$ em água, para todos os usos avaliados, encontram-se baixos. Estão associados à própria geologia local e seus minerais, caracterizando solos fortemente ácidos, entre 4 e 5 (WUTKE, 1972), que são prejudiciais para alguns tipos de cultivo.

Segundo Meurer, Bissani e Camona (2012), valores de $\mathrm{pH}$ abaixo de 5,5 torna possível altas concentrações de alumínio trocável e que, acima do $\mathrm{pH}$ referido, - $\mathrm{Al}^{3+}$ torna-se insolúvel e se apresenta na forma de hidróxido de alumínio e, portanto, não tóxico para as raízes das plantas. Além disso, o $\mathrm{pH}$ abaixo de 5,5 diminui a disponibilidade de molibdênio e fósforo, pois são altamente fixados pelo ferro, alumínio, manganês e titânio, que se encontram altamente solúveis, ao constituir, também, elementos importantes para o desenvolvimento do sistema radicular e frutificação.

A importância da agricultura familiar para a região e o escoamento da produção para o abastecimento das grandes cidades se faz importante atentar, também, para a qualidade química desses solos frente ao uso e ao manejo realizado, haja vista sua influência direta na qualidade da produção agrícola ainda que em pequena escala.

\section{CONSIDERAÇÕES FINAIS}

Os resultados obtidos nas condições desta pesquisa permitem concluir que a retirada da vegetação e sua substituição por pastagens, agricultura familiar e/ou ocupação desordenada podem vir a contribuir para o aumento do aporte de sedimentos das encostas da sub-bacia hidrográfica do rio São Romão para as calhas fluviais do médio e baixo curso da bacia hidrográfica do rio Macaé, pois aumentam a carga de fundo e podem resultar no assoreamento devido às formas de uso e manejo do solo encontrado. 
A retirada da vegetação para fins agrícolas pode trazer como consequência a mudança do microclima da região assim como a alteração dos solos. Além disso, a identificação de feições erosivas como terracetes (derivados do pisoteio do gado) e ravinas, aponta um indicativo de que as condições da qualidade dos solos nessas áreas foram alteradas, resultado que poderá ser verificado pelas análises de densidade aparente e porosidade do solo.

Dos três usos do solo avaliados, a floresta foi a que melhor apresentou qualidade física e química, ao se destacar com as análises de densidade aparente e carbono orgânico. Embora a floresta avaliada seja secundária e apresente perturbações (quanto ao desmatamento pelo avanço de outros usos e a ocupação urbana), a literatura que embasou a pesquisa informa boas condições físicas e químicas para esses solos. Entretanto, o turismo vem ganhando força e gerando uma ameaça à Área de Proteção Ambiental Estadual de Macaé de Cima.

A área de cultivo, representada pelo plantio de açaí, mostra resultados intermediários nas análises físicas e químicas dos solos. Admite-se que o "descanso" da terra através do pousio (que varia de acordo com o último plantio), entre rotação de culturas, esteja trazendo indicadores melhores de qualidade dos solos do que os da pastagem. Além disso, os valores intermediários apresentados vêm do fato de cultivar a terra para o próprio consumo e com baixa relação comercial. Entretanto, é importante considerar que existem outros tipos e formas de cultivos de subsistência e agricultura familiar dentro da sub-bacia hidrográfica do rio São Romão, sendo importante conhecê-los em estudos futuros.

Por último, tem-se a pastagem que apresenta os piores resultados das análises físicas e químicas, o que resulta em um uso com maior suscetibilidade à erosão. Dos dados avaliados, a densidade aparente foi a mais significativa, ao mostrar ser o solo ácido mais compactado em relação aos demais. Assim, os usos do solo apresentam a seguinte ordem de suscetibilidade à erosão: pastagem>cultivo>floresta.

As análises realizadas para essa pesquisa não conseguem compreender a totalidade dos processos que ocorrem ou podem vir a ocorrer em sua essência e necessitam da realização de mais estudos nessa região, como, por exemplo, testes de infiltração associados a ensaios de estabilidade dos agregados em água para que sejam mais bem compreendidos os processos erosivos atuantes na dinâmica ambiental do geossistema. Acrescenta-se, também, que este estudo é fundamental no subsídio às pesquisas que são desenvolvidas dentro da bacia hidrográfica do rio Macaé, em especial para a APA de Macaé de Cima, no que tange ao aumento dos remanescentes florestais nas cabeceiras de drenagem, identificação de processos erosivos e melhoria da qualidade da água nas bacias hidrográficas que a contemplam.

Há a apreensão de que se os órgãos governamentais não aumentarem a fiscalização em relação ao surgimento de novas moradias e gestão do uso do solo, em pouco tempo, o cenário da sub-bacia hidrográfica estudada poderá ser modificado, corroborando para o surgimento de novas cicatrizes na paisagem em detrimento das características ambientais que a região Serrana apresenta.

\section{AGRADECIMENTOS}


Influência do manejo...

À Fundação de Amparo à pesquisa do Estado do Rio de Janeiro (FAPERJ) e ao Instituto Federal do Rio de Janeiro (IFRJ) pelo financiamento dessa pesquisa.

\section{REFERÊNCIAS}

AB'SABER, A. N. Os domínios de natureza no Brasil: Potencialidades paisagísticas. São Paulo: Ateliê Editorial, 2003. 9-33p.

BAYER, C.; MIELNICZUC, J. Dinâmica e função da matéria orgânica. In: SANTOS, G. A.; SILVA, L. S.; CANELLAS, L. P.; CAMARGO, F. A. O. (Ed) Fundamentos da matéria orgânica do solo - Ecossistemas tropicais e subtropicais. Porto Alegre: Metrópole, 2008. p. 7-16.

BIGARELLA, J. J; BECKER, D. R; SANTOS, F. G. Estrutura e origem das paisagens tropicais e subtropicais II. 2. ed. Florianópolis: UFSC, 2007. p.434530.

BOARDMAN, J. Prefácio. In: GUERRA, A. J. T; SILVA, A. S. da; BOTELHO, R. G. M. (Orgs). Erosão e conservação dos solos: conceitos, temas e aplicações. 4. ed. Rio de Janeiro: Bertrand Brasil, 2009. p.17-55.

BRADY, N. C. Natureza e propriedade dos solos. 7. ed. Trad. Antônio B. Neiva Figueiredo. Rio de Janeiro: Freitas Bastos, 1989. 878p.

BRASIL. Levantamento de recursos naturais. Folha SF. 23/24 Rio de Janeiro/Vitória; geologia, geomorfologia, pedologia, vegetação e uso potencial da terra/ Projeto RADAMBRASIL - Rio de Janeiro, 1983.

CARNEIRO, M. A.; SOUZA, E. D.; REIS, E. F.; PEREIRA, H. S.; AZEVEDO, W. R. Atributos físicos, químicos e biológicos de solo de Cerrado sob diferentes sistemas de uso e manejo. Revista Brasileira de Ciência do Solo, Viçosa, v. 33, n. 1, p. 147157. Jan.-Fev. 2009.

COELHO NETTO, A. L. Hidrologia de encosta na interface com a geomorfologia. In: GUERRA, A. J. T.; CUNHA, S. B. DA (Org). Geomorfologia: Uma atualização de bases e conceitos. Rio de Janeiro: Bertrand Brasil, 2009. 9. ed. p. 93-144.

DANTAS, M. E. Geomorfologia do Estado do Rio de Janeiro. Texto explicativo do mapa geomorfológico do Estado do Rio de Janeiro. Brasília: CPRM. 2. Ed. revisada em 2001.

EMBRAPA. Manual de métodos de análise de solo. 2. ed. Rio de Janeiro: Embrapa solos, 2011.

EMBRAPA. Mapa de reconhecimento de baixa intensidade dos Solos do estado do Rio de Janeiro. Ministério da Agricultura, pecuária e do Abastecimento, 2003.

EMBRAPA. Sistema Brasileiro de Classificação de Solos. 2. ed. Rio de Janeiro: Embrapa Solos, 2013.

GUERRA. A. J. T. O papel da matéria orgânica e dos agregados na erodibilidade dos solos. Anuário do Instituto de Geociências da UFRJ, v.13. p.43-52. 1990.

GUERRA. A. J. T., O processo erosivo nas encostas. In: GUERRA, A. J. T.; CUNHA, S. B. DA (Org). Geomorfologia: Uma atualização de bases e conceitos. Rio de Janeiro: Bertrand Brasil, 2009. 9. ed. p. 149-199. 
GUERRA. A. J. T.; BOTELHO, R. G. M. Características e propriedades dos solos relevantes para os estudos pedológicos e análise dos processos erosivos. Anuário do Instituto de Geociências da UFRJ, v.19. p.93-114. 1996.

GROSBELLET, C.; VIDAL-BEAUDET, L.; CAUBEL, V.; CHARPENTIER, S. 2011. Improvement of soil structure formation by degradation of coarse organic matter. Geoderma 162, 27-38. Jan-Fev. 2011.

HORTON, R. E. Erosional development of streams and their drainage basins; hydrophysical approach to quantitative morphology. Geol. Soc America Bulletin, v.3, n.56, p. 275-370. Mar.1945.

ICMBio. Reservas Particulares Do Patrimônio Natural - Rppn. Disponível em:

http://sistemas.icmbio.gov.br/simrppn/publico/detalhe/377/. Acesso em Junho de 2016.

INEA. O estado do ambiente: Indicadores ambientais do Estado do Rio de Janeiro. Rio de Janeiro: SEA; INEA, 2011. 160p.

INEA. Relatório de caracterização e mapeamento do uso do solo e cobertura vegetal da região hidrográfica Macaé e Rio das Ostras - versão preliminar. 47p. 2012. Disponível em: http://planomacaeostras.com/pdf/EG0143-R-PRH-RD-03-00.pdf

KIEHL, E. D. Manual de edafologia: relações solo-planta. São Paulo: Editora Agronômica Ceres, 1979.

LAL, R. Métodos para a avaliação do uso sustentável dos recursos solo e água nos trópicos. Tradução: Claúdio Conti Medugno e José Flávio Dyania. Jaguariúna: Embrapa Meio Ambiente, p. 97. (Embrapa Meio Ambiente - Documentos, 03). 1999.

LARSON, W. E.; PIERCE, F. J. The dynamics of soil quality as a measure of sustainable management. In: DORAN, J.W.; COLEMAN, D. C.; BEZDICEK, D. F.; STEWART, B. A. (Eds) Defining soil quality for a sustainable environment. Madison; Soil Science Society of America, 1994.

LIMA, L. D. M.; SILVEIRA, P. G.; SILVA, F. F.; LOUREIRO, H. A. S. Estudo dos Processos Erosivos no Médio e Alto Curso da Bacia Hidrográfica do Rio Macaé, Macaé/RJ. Geografia. Ensino \& Pesquisa. UFSM, v. 12, p. 000-000. 2008.

LOUREIRO, H. A. S. Monitoramento e diagnóstico de áreas degradadas na bacia hidrográfica do rio são pedro $(\mathrm{RJ})$ - Estudos Experimentais em Voçoroca e Utilização de Geotêxteis de Fibra de Bananeira. 214p. Dissertação submetida ao Programa de Pós-Graduação em Geografia da UFRJ. Rio de Janeiro, 2013.

LOUREIRO, H.A.S.; NEVES, S.R.A.; BRIZZI, R.R.; MENDES, S.P.; GUERRA, A.J.T. Soil Erodibility and Monitoring at a Gully in São Pedro River's Drainage Basin, Macaé Municipality/Rio de Janeiro State - Brazil. In: UGI 2011 - Regional Geographic Conference, 2011, Santiago. Conference Proceedings - Regional Geographic Conference UGI 2011. Santiago, 2011.

MEDINA, H. P. Água no solo. In: Elementos de pedologia. MONIZ, A. C. (Org). Rio de Janeiro: Livros técnicos e científicos, 1972. p.45-56.

MENDES, S. P. Identificação e avaliação da paisagem da Área de Proteção Ambiental de Macaé de Cima (RJ). 136p. Dissertação submetida ao Programa de Pós-Graduação em Geografia da UFRJ. Rio de Janeiro, 2010. 
MEURER, E. J.; BISSANI, C. A.; CAMONA, F. C. Solos afetados por sais. In: MEURER, E. J. (Org). Fundamentos de Química do Solo. 5. ed. Porto Alegre: Evangraf, 2012. p.155-174.

NASCIMENTO, F. J. B.; HINGEL, R. de L.; SOUSA, P. A. de; MARÇAL, M. S. (2010). Caracterização espaço-temporal das chuvas associada às vazões na bacia do rio Macaé - RJ. In: IX Simpósio Brasileiro de Climatologia Geográfica (Anais). Fortaleza: UFC. CD-ROM.

PINHEIRO, M. R. C.; SILVA, F. E.; PRIOSTE, M. A.; FERREIRA, M. I. P. Avaliação da qualidade da água na bacia hidrográfica do rio Macaé e aplicação do índice de qualidade de água. In: II Simpósio de Recursos Hídricos Sul-Sudeste, 2008, Rio de Janeiro.

RADAM. Levantamento de recursos naturais. Brasil, v. 32, 780p., 1983.

REICHARDT, K. A água em sistemas agrícolas. Manole, 1987.

RESENDE, M.; CURI, N.; REZENDE, S. B. DE; CORRÊA, G. F. Pedologia: base para distinção de ambientes. 5. ed. Lavras: UFLA, 2007. 322p.

SANTOS, J. L. S.; MADARI, B. E.; COSTA, A. R. FERNANDES, E. P.; MACHADO, P. L. O. A. Avaliação dos parâmetros físicos do solo em sistema integração lavourapecuária implantado em pasto degradado. In: XXXIII congresso brasileiro de ciência do solo, 2010, Uberlândia/Minas Gerais.

SILVA, R. C. S.; ALMEIDA, J. C. R.; BATISTA, G. T.; FORTES NETO, P.; Os indicadores físicos, químicos e biológicos da qualidade do solo e da sustentabilidade dos ambientes naturais. Repositório Eletrônico Ciências Agrárias, Coleção Ciências Ambientais. p. 1-13, 2011.

VARGAS JR., E. A.; NUNES, A. L. L. S. Noções de mecânica das rochas. Rio de Janeiro: PUC/RJ, 1992. 191p. (Notas de aula).

WUTKE, A. C. P. Acidez. In: MONIZ, A. C. (Org) Elementos de pedologia. Rio de Janeiro: Livros técnicos e científicos, 1972. p.149-177. 